\title{
DESIGN, CHARACTERIZATION AND ENHANCED BIOAVAILABILITY OF HYDROXYPROPYLCELLULOSE-BASED NOVEL BIOCONJUGATES FOR INCLUSION OF A FLUOROQUINOLONE ANTIBIOTIC - GEMIFLOXACIN
}

\author{
MUHAMMAD AJAZ HUSSAIN, " IRAM MALIK, IQRA SHAD, , FASIHA AMJAD, \\ MUHAMMAD AMIN, ${ }^{* *}$ MUHAMMAD NAWAZ TAHIR, ${ }^{* * *}$ NISAR ULLAH, ${ }^{* * *}$ MUHAMMAD \\ ASHRAF $^{* * * *}$ and MUHAMMAD IMRAN IRFAN* \\ *Institute of Chemistry, University of Sargodha, Sargodha, 40100, Pakistan \\ ${ }^{* *}$ Department of Chemistry, University of Lahore, Sargodha Campus, Sargodha 40100, Pakistan \\ ${ }^{* * * * *}$ Chemistry Department, King Fahd University of Petroleum and Minerals, \\ Dhahran 31261, Saudi Arabia \\ \Corresponding author: M. A. Hussain,majaz172@yahoo.com
}

Received August 8, 2021

Polysaccharides are beneficially used as drug carriers via prodrug formation and offer a mechanism for better effectiveness and delivery of the drug. The unique geometry of hydroxypropylcellulose (HPC), a polysaccharide, allows the attachment of drug molecules with a higher degree of substitution. Therefore, HPC-gemifloxacin conjugates, i.e., macromolecular prodrugs, were synthesized using acylation reagents, i.e., tosyl chloride and carbonyldiimidazole using $N, N$-dimethylacetamide as a solvent. The reactions were carried out at $80^{\circ} \mathrm{C}$ under stirring for $24 \mathrm{~h}$ in inert environment. This strategy of reaction appeared efficient to obtain a high degree of drug substitution (DS $=0.42-1.34$ ) on the polymer parent chain, as calculated by UV-visible spectrophotometry after hydrolysis of the samples. The method provides high efficacy as product yields were high (71-76\%). Macromolecular prodrugs with different DS of gemifloxacin (GEM) designed were found soluble in organic solvents. The pharmacokinetic studies showed that the $\mathrm{t}_{1 / 2}$ and $t_{\max }$ values of GEM from HPC-GEM conjugate were considerably higher, which indicates improved bioavailability of the drug after conjugate formation.

Keywords: esterification, hydroxypropylcellulose, gemifloxacin, pharmacokinetics, macromolecular prodrugs, fluoroquinolone antibiotics

\section{INTRODUCTION}

Gemifloxacin (GEM) is a latest fluoroquinolone antibiotic, having a broadspectrum antibacterial activity, which is used to treat a wide range of pathogens. It has demonstrated potent activity with improved affinity, as compared to other drugs active against respiratory tract pathogens, such as Haemophillus influenzea, Moraxella catarahallis and Streptococcus pneumoniea etc. ${ }^{1-3}$ Several common side effects are linked with GEM, i.e., diarrhea, nausea, abdominal pain, headaches, skin rash and allergic reactions. ${ }^{4}$ The less common, but more severe side effects of the fluoroquinolone antibiotics include seizures, hallucinations, tendon rupture, severe hypersensitivity reactions, Stevens Johnson syndrome, angioedema and photosensitivity. ${ }^{5-7}$ Such side effects of the drugs can be minimized in several ways, and one of the important methods is to make their prodrugs with polysaccharide ethers. In this way, one may get patient compliance due to reduction in dose/frequency and sustained/targeted release of the drug, if it is in the macromolecular prodrug (MPD) form. ${ }^{8}$

In these days, the researchers' interest is focused on the use of polysaccharide materials for the development of NSAIDs and antibiotic MPDs, ${ }^{9}$ and amongst polysaccharides, hydroxypropylcellulose (HPC) has gained a high rank. ${ }^{10,11}$ It is due to the fact that in HPC a higher degree of drug substitution can be achieved due to its stereochemical structure, as the hydroxyl groups of the polymer are projected outside the chains. From these achievements and 
investigations in the field of prodrug formation, it is evident that there is a vast ground for the employment of HPC in advanced drug delivery as a macromolecular carrier of drugs.

So, the present study targets the synthesis of novel MPDs of antibiotic gemifloxacin (GEM) based on a biocompatible, biodegradable, nontoxic and hydrophilic cellulose ether derivative, HPC. We have fabricated the MPDs of GEM using efficient reaction methodologies, i.e., activation of GEM with tosyl chloride (Tos-Cl) and 1,1'-carbonyldiimidazole (CDI) to get its MPDs with HPC. Besides the synthesis of novel prodrugs of GEM, our aim has been to reduce its side effects by improving its pharmacokinetic profile by MPD formation and sustained release. Pharmacokinetic/bioavailability studies of the HPC-gemifloxacin (HPC-GEM) conjugates were carried out in rabbit models.

\section{EXPERIMENTAL \\ Materials}

HPC (DS 3.00, MS 3.46, Mw $1.16 \times 10^{5}$ ) was purchased from Nanjing Yeshun Industry and International Trading Co. Ltd., Jiangsu, China, and first dried completely at $110^{\circ} \mathrm{C}$ for $10 \mathrm{~h}$ before use in the reaction. 1,1'-Carbonyldiimidazole (CDI; mol. weight: $162.15 \mathrm{~g} / \mathrm{mol}$, m.p.: $\left.117-122{ }^{\circ} \mathrm{C}\right)$, 4methylbenzenesulfonyl chloride (tosyl chloride; mol. weight: $190.65 \mathrm{~g} / \mathrm{mol}$, m.p. $65-69{ }^{\circ} \mathrm{C}$ ), imidazole, $\mathrm{NaOH}$, ethanol and methanol were purchased from Sigma-Aldrich, USA. Gemifloxacin mesylate (GEM) was received as a gift from Candid Pharmaceuticals, Sialkot, Pakistan, as per US Pharmacopoeia standard. $\mathrm{N}, \mathrm{N}$-dimethylacetamide (DMAc; mol. weight: 87.12 $\mathrm{g} / \mathrm{mol}$, b.p. $164.0{ }^{\circ} \mathrm{C}$ ) was purchased from ACROS Organics. Diethyl ether was procured from Lab Scan; acetone was obtained from Merck. Dimethylsulfoxide (DMSO; mol. weight: $78.13 \mathrm{~g} / \mathrm{mol}$ ) was purchased from Panreac Sintesis, Barcelona. Regenerated cellulose tubular membrane (wall thickness $23 \mu \mathrm{m}$, dry cylinder diameter $21.0 \mathrm{~mm}$ ) with nominal MWCO value of $12000-14000$ was procured from Cellu•Sep ${ }^{\circledR}$ T4 (USA). Deionized water was used for research purpose.

\section{Measurements}

FTIR spectra of the products were recorded on an IR Prestige-21 (Shimadzu, Japan) spectrometer, preparing tablets of materials by pressing with $\mathrm{KBr}$ before analysis. The contents of the drug in the prodrugs were calculated using a UV PharmaSpec 1700, Shimadzu, Japan. The structures of the conjugates were determined using ${ }^{1} \mathrm{H}$-NMR (500 $\mathrm{MHz}$ ) in DMSO- $d_{6}$ (Bruker Avance, Germany). To get a pharmacokinetic profile of the prodrugs, an HPLC/UV method was developed. The HPLC system
(Agilent Technologies 1200 Series, Germany) was set up with a UV detector (G1315B DAD), a pump (G1311A) and a degasser (G1322A). Shim-Pack columns (ODS $5 \mu \mathrm{m}, 4.6 \times 250 \mathrm{~mm}$ ) were used for elution.

\section{Molar calculation of the reactants}

Calculation of molar mass of a repeating unit of HPC

The following formula was used to calculate the molar mass of a HPC repeating unit:

Molar mass of HPC repeating unit =

[ mass of $\mathrm{AGU}+($ mass of $\mathrm{HP} \times M S)-D S]$

$=[162.14+(59 \times 3.46)-3]=363.28 \mathrm{~g} / \mathrm{mol}$

where $\mathrm{AGU}$ is anhydroglucose unit, $\mathrm{HP}$ is hydroxypropyl moiety, MS is molar substitution of HP onto HPC, DS is degree of substitution of HP onto the $\mathrm{OH}$ groups of the AGU.

\section{Calculation of amounts of GEM, CDI, Tos-Cl and Imidazole}

The following formula was used to calculate the amounts of reactants:

Amount of reactants $=[$ moles of HPC $\times$

$\times$ molar mass of reagent $\times$ molar ratio of reagent]

\section{Synthesis of HPC-GEM conjugate 1, a typical example}

The HPC (1.0 g, $2.75 \mathrm{mmol})$ was dried (60 min, $\left.110^{\circ} \mathrm{C}\right)$, then added in DMAc $(30 \mathrm{~mL})$ and stirred $(30$ min, $\left.80{ }^{\circ} \mathrm{C}\right)$ to dissolve. Acylating agent Tos- $\mathrm{Cl}(0.52$ $\mathrm{g}, 2.75 \mathrm{mmol}$ ) was added to the solution and stirred continuously, followed by the addition of the imidazole $(0.37 \mathrm{~g}, 5.50 \mathrm{mmol})$ as a base. GEM (1.07 g, $2.75 \mathrm{mmol}$ ) was added and the reaction mixture was kept under stirring $\left(24 \mathrm{~h}, 80^{\circ} \mathrm{C}\right)$ and under nitrogen environment. After cooling of the reaction mixture at room temperature, the product HPC-GEM conjugate 1 was extracted from the reaction mixture by precipitation in diethyl ether $(200 \mathrm{~mL})$. The precipitates were obtained and washed thrice with diethyl ether $(100 \mathrm{~mL})$ to remove unreacted reactants and side product and dried overnight at $50{ }^{\circ} \mathrm{C}$ under vacuum.

HPC-GEM conjugate $\mathbf{1}$; DS $=0.42$ by UV/Vis spectrophotometry; Yield: 71\%; FTIR (KBr): 2895$3473(\mathrm{OH}), 1718\left(\mathrm{CO}_{\text {ester }}\right), 1442\left(\mathrm{CH}_{2}\right), 1051(\mathrm{COC})$ $\mathrm{cm}^{-1}$.

HPC-GEM conjugate $2 ; \mathrm{DS}=0.55$ by $\mathrm{UV} / \mathrm{Vis}$ spectrophotometry; Yield: 73\%; FTIR (KBr): 2902$3458(\mathrm{OH}), 1722\left(\mathrm{CO}_{\text {ester }}\right), 1458\left(\mathrm{CH}_{2}\right), 1053(\mathrm{COC})$ $\mathrm{cm}^{-1}$.

HPC-GEM conjugate 3 ; $\mathrm{DS}=0.65$ by $\mathrm{UV} / \mathrm{V}$ is spectrophotometry; Yield: 75\%; FTIR (KBr): 2889$3483(\mathrm{OH}), 1728$ ( $\left.\mathrm{CO}_{\text {ester }}\right), 1463\left(\mathrm{CH}_{2}\right), 1051(\mathrm{COC})$ $\mathrm{cm}^{-1} ;{ }^{1} \mathrm{H}$ NMR $\left(\delta \mathrm{ppm} ; 500 \mathrm{MHz}, \mathrm{DMSO}-d_{6}\right): 6.93(\mathrm{H}$ $12,14), 7.42$ (H 13) and 7.76 (H 11), 3.17-4.73 (H 1$8)$. 


\section{Synthesis of HPC-GEM conjugate 4}

In the second method of prodrug formation, the CDI (0.45 g, $2.75 \mathrm{mmol})$ was added in DMAc (30 $\mathrm{mL})$, followed by the addition of gemifloxacin $(1.07 \mathrm{~g}$, $2.75 \mathrm{mmol}$ ) and stirred for $24 \mathrm{~h}$ at room temperature. The HPC ( $1 \mathrm{~g}, 2.75 \mathrm{mmol})$ was dissolved separately in DMAc $(20 \mathrm{~mL})$ under stirring $\left(80{ }^{\circ} \mathrm{C}, 1.5 \mathrm{~h}\right)$. The reaction mixture, i.e., GEM/CDI and pre-dissolved HPC were mixed and the reaction was then carried out at $80{ }^{\circ} \mathrm{C}$ for $24 \mathrm{~h}$, along with stirring under nitrogen. The reaction mixture was then cooled to room temperature and the product HPC-GEM conjugate $\mathbf{4}$ was precipitated from the reaction mixture in diethyl ether $(250 \mathrm{~mL})$. Washing of the precipitates was also carried out with diethyl ether $(50 \mathrm{~mL})$ thrice, followed by drying in a vacuum oven $\left(50{ }^{\circ} \mathrm{C}\right.$ for $\left.24 \mathrm{~h}\right)$.

HPC-GEM conjugate $4 ; \mathrm{DS}=0.90$ by $\mathrm{UV} \backslash \mathrm{V}$ is spectroscopy, Yield: 73\%, FTIR (KBr): 2923-3558 $(\mathrm{OH}), 1727\left(\mathrm{CO}_{\text {ester }}\right), 1453\left(\mathrm{CH}_{2}\right), 1057(\mathrm{COC}) \mathrm{cm}^{-1}$.

HPC-GEM conjugate 5; $\mathrm{DS}=1.34$ by $\mathrm{UV} / \mathrm{Vis}$ spectrophotometry; Yield: 76\%; FTIR (KBr): 2902$3458(\mathrm{OH}), 1722\left(\mathrm{CO}_{\text {ester }}\right), 1458\left(\mathrm{CH}_{2}\right), 1053(\mathrm{COC})$ $\mathrm{cm}^{-1}$.

\section{Determination of degree of substitution (DS) by UV/Vis spectroscopy}

The DS of HPC-GEM conjugates $\mathbf{1 - 5}$ were calculated by UV/Vis. The standard solutions of GEM were prepared from 2-20 ppm concentration by using aq. solution of $\mathrm{NaOH}(0.1 \mathrm{~N})$. Solutions of conjugates were prepared by dissolving conjugates (10 mg each) in aq. solution of $\mathrm{NaOH}(0.1 \mathrm{~N}, 10 \mathrm{~mL})$. These solutions were then stirred $\left(80{ }^{\circ} \mathrm{C}, 2 \mathrm{~h}\right)$ to hydrolyse the conjugate to release the free drug. After hydrolysis, the volume of solutions was made up to $10 \mathrm{~mL}$ and further dilutions were made of the aq. solution of $\mathrm{NaOH}(0.1 \mathrm{~N})$. The calibration curves were drawn as concentration $v s$. absorbance by the UV/Vis spectrophotometer at $\lambda_{\max } 260 \mathrm{~nm}$. The amount of drug (mg of drug/100 mg of conjugate) was determined by standard solution calibration curves of GEM, thus, drug contents were determined and then converted to DS of drug onto polymer.

\section{Pharmacokinetic analysis}

A simple, efficient and rapid reverse phase (RP) HPLC/UV method was developed for the examining the pharmacokinetic profile of prodrugs of GEM. To evaluate drug content (DC), drug purity and the pharmacokinetic profile of the prodrug, the method was validated according to the International Council for Harmonization ( $\mathrm{ICH}$ ) guidelines. The mobile phase was acetonitrile:methanol:water (30:30:40 v/v) and $\lambda_{\max } 263 \mathrm{~nm}$ was used. The flow rate of the mobile phase was $1 \mathrm{~mL} \mathrm{~min}^{-1}$ with $10 \mu \mathrm{L}$ injection volume in each run. A stock solution of $1000 \mathrm{ppm}$ of the drug and prodrug was prepared separately by dissolving $100 \mathrm{mg}$ of each in $100 \mathrm{~mL}$ of mobile phase. The desired concentrations were prepared by diluting this stock solution. All standard solutions of the drug and the prodrug were sonicated. They were filtered through a nylon syringe filter $(0.45 \mu)$ before transferring them into HPLC vials. All chromatographic separations were performed in the isocratic mode.

\section{RP-HPLC/UV method validation}

The ICH guidelines were followed for the validation of the HPLC/UV method, prior to pharmacokinetic studies of the prodrugs. Different validation parameters were studied and are summarized below.

\section{Accuracy, linearity and precision}

The accuracy of the method was determined in terms of percentage recovery. For this purpose, different samples were spiked with a known amount of prodrug solutions and the percentage recovery was calculated by the amount of sample recovered. Using a range of standard solutions $(5-50 \mu \mathrm{g} / \mathrm{mL})$ of the prodrug, linearity in the analytical response in all methods was confirmed. The calibration curves for each prodrug were constructed from chromatograms obtained after injecting $10 \mu \mathrm{L}$ of each sample and the $r^{2}$ value was determined by the linear regression method. Precision was determined by replicate runs (six) of the standard solution $(10 \mu \mathrm{g} / \mathrm{mL})$ of the prodrug and relative standard deviations (RSD) were also determined. Intra-day precision and inter-day precisions were also determined to check the variability of the method.

\section{Robustness and specificity}

The robustness of the method was confirmed by changing the column temperature, composition, flow rate of the mobile phase and $\mathrm{pH}$. Chromatograms didn't show any significant change during these observations. Using optimized chromatographic techniques, a blank solution of drug and the standard solution $(10 \mu \mathrm{g} / \mathrm{mL})$ of the drug were used to check the specificity of the method. The resulting chromatograms showed no appearance of any impurity, which confirmed the specificity of the method.

Limit of detection (LOD), limit of quantification (LOQ) and stability study

The LOD was calculated by eluting dilute solutions of certain known concentrations till the final response, which is equal to three times the signal to noise ratio. LOQ was maintained ten times higher than the signal to noise ratio. Prior to analysis, the stability of the sample was checked in the mobile phase. It was confirmed that no sample degradation took place and the stability study was extended to $72 \mathrm{~h}$.

\section{Pharmacokinetic studies}

\section{Study design and participants}

To study the pharmacokinetics of each drug and prodrug, two sets of six healthy albino male rabbits 
$(\approx 1.5 \mathrm{~kg}$ each) were marked. All the rabbits were kept in a $12 \mathrm{~h}$ light and $12 \mathrm{~h}$ dark cycle. Both sets were kept under fasting for $10 \mathrm{~h}$ with ad libitum access to water. After this, GEM (16.5 mg/kg = $25 \mathrm{mg}$ drug) and the HPC-GEM conjugate ( $63 \mathrm{mg}$ conjugate $=25 \mathrm{mg}$ drug $)$ were administered to each set separately, and the rabbits were kept under observation. They were allowed to take water after $1 \mathrm{~h}$ of the drug administration and standard green food after $5 \mathrm{~h}$. The study procedures where animal models are used have been approved by the Institutional Research Ethics Committee of The University of Lahore. The studies on animal models were in agreement with the directions of the National Institute of Health's Guidelines for the Care and Use of Laboratory Animals (NIH Publications No. 8023, revised 1978). Experimental protocols are duly approved (IAEC2016-15B; dated 27-01-2016) by the Institutional Research Ethics Committee of The University of Lahore.

\section{Specimen collection and storage}

Heparinized disposable syringes (Injekt ${ }^{\circledR} \mathrm{B}$. Braun) were used to collect blood samples $(3-5 \mathrm{~mL})$ from the jugular vein at particular time periods. The blood samples were collected in blood vials and centrifuged at $3500 \times \mathrm{g}$ for $10 \mathrm{~min}$ to separate plasma. The samples were then kept in a freezer at $-10{ }^{\circ} \mathrm{C}$ for further analysis.

\section{Plasma sample preparation}

Plasma samples were mixed with a mixture of acetonitrile and methanol (1:1) and precipitated. The samples were then centrifuged $3000 \times \mathrm{g}$ and precipitates were separated. The clear supernatant was extracted by a syringe and filtered by a $0.45 \mu$ nylon syringe before placing it into the HPLC/UV apparatus.

\section{Pharmacokinetic evaluation}

Plots of plasma concentration $v s$. time for the drug and the conjugate were constructed using Microsoft Excel® 2010. Various pharmacokinetic parameters, such as time to peak drug conc. $\left(\mathrm{t}_{\max }\right)$, area under the curve from time zero to time $\mathrm{t}\left(\mathrm{AUC}_{0-\mathrm{t}}\right)$, area under the curve from time zero to time infinity $\left(\mathrm{AUC}_{0-\infty}\right)$, halflife of drug $\left(\mathrm{t}_{1 / 2}\right)$, peak drug conc. $\left(\mathrm{C}_{\max }\right)$, volume of distribution $(\mathrm{Vd})$ and clearance $(\mathrm{CI})$ were calculated by using the trapezoidal method.

\section{RESULTS AND DISCUSSION} Synthesis of HPC-GEM conjugates 1-3 using tosyl chloride (Tos-CI)

The GEM reacts first with Tos-Cl in DMAc medium to make their tosylate derivative, which then reacts with the hydroxyl groups situated on the HPC polymer. As the tosylate moiety is a good leaving group, hence it can be easily removed upon the esterification ${ }^{12}$ with the HPC polymer due to the nucleophilic action of the hydroxyl groups of the polymer. HPC-GEM conjugates 1-3 were synthesized under homogeneous reaction conditions. The MPDs 1-3 showed DS 0.42-0.65, as calculated from the UV absorption data of the drug after hydrolysis.
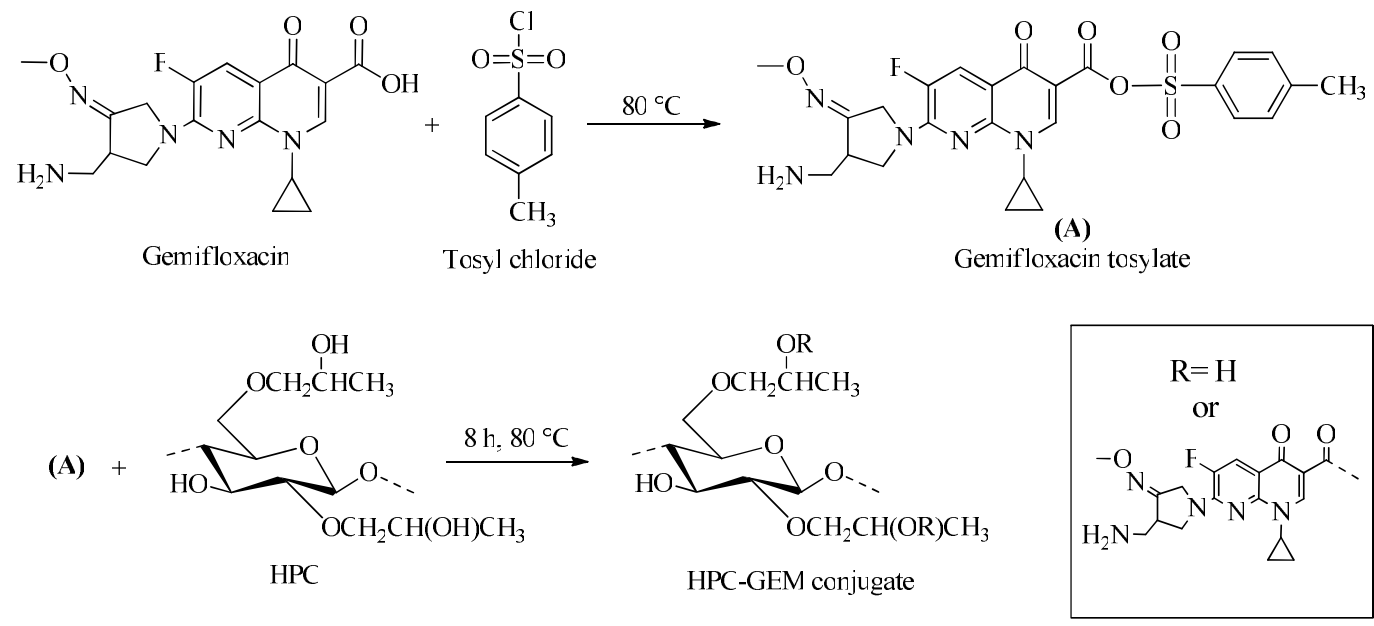

Figure 1: Synthesis of HPC-GEM conjugates 1-3, applying in situ activation of GEM with Tos-Cl

Figure 1 presents a general pathway for fabricating the esterified HPC-GEM prodrug using Tos-Cl as activating agent. All the conjugates 1-3 were soluble in different organic solvents, such as dimethyacetamide (DMAc), dimethylsulfoxide (DMSO), dimethylformamide 
(DMF) and water. Table 1 summarizes the data regarding the mole ratio, yield, DC, DS and solubility of HPC-GEM conjugates 1-3.

\section{Synthesis of HPC-GEM conjugates 4-5 using CDI}

The prodrugs of GEM with HPC were synthesized using a homogenous methodology widely accepted for the esterification reaction of cellulose and related polysaccharide materials. ${ }^{13,14}$
In the first step, in situ activation of the carboxylic group of GEM was done with an efficient acylating reagent, i.e., $N, N^{\prime}$ carbonyldiimidazole (CDI) just by mixing both them in DMAc and stirring $(24 \mathrm{~h})$. The imidazolide of GEM formed and then reacted efficiently with the $\mathrm{OH}$ groups present on the polymer to form ester MPDs. The reaction was carried out in a homogeneous phase. The reaction scheme is shown in Figure 2.

Table 1

Results and conditions for reaction of HPC $(1 \mathrm{~g})$ with GEM after in situ activation with Tos- $\mathrm{Cl}$ at $80^{\circ} \mathrm{C}$ for $24 \mathrm{~h}$

\begin{tabular}{cccccc}
\hline Sample & Mole ratio $^{\mathrm{a}}$ & Yield $(\mathrm{g}, \%)^{\mathrm{D}} \mathrm{DC}$ & ${ }^{\mathrm{b}} \mathrm{DS}$ & Solubility \\
\hline $\mathbf{1}$ & $1: 1: 1: 2$ & 71 & 30 & 0.42 & DMSO, DMAc, DMF, Water \\
$\mathbf{2}$ & $1: 2: 2: 4$ & 73 & 36 & 0.55 & DMSO, DMAc, DMF, Water \\
$\mathbf{3}$ & $1: 3: 3: 6$ & 75 & 40 & 0.65 & DMSO, DMAc, DMF, Water \\
\hline
\end{tabular}

${ }^{\mathrm{a}} \mathrm{HPC}$ : Tos-Cl: Gemifloxacin: Imidazole; ${ }^{\mathrm{b}} \mathrm{DS}$ calculated from DC (by using UV/Vis data)
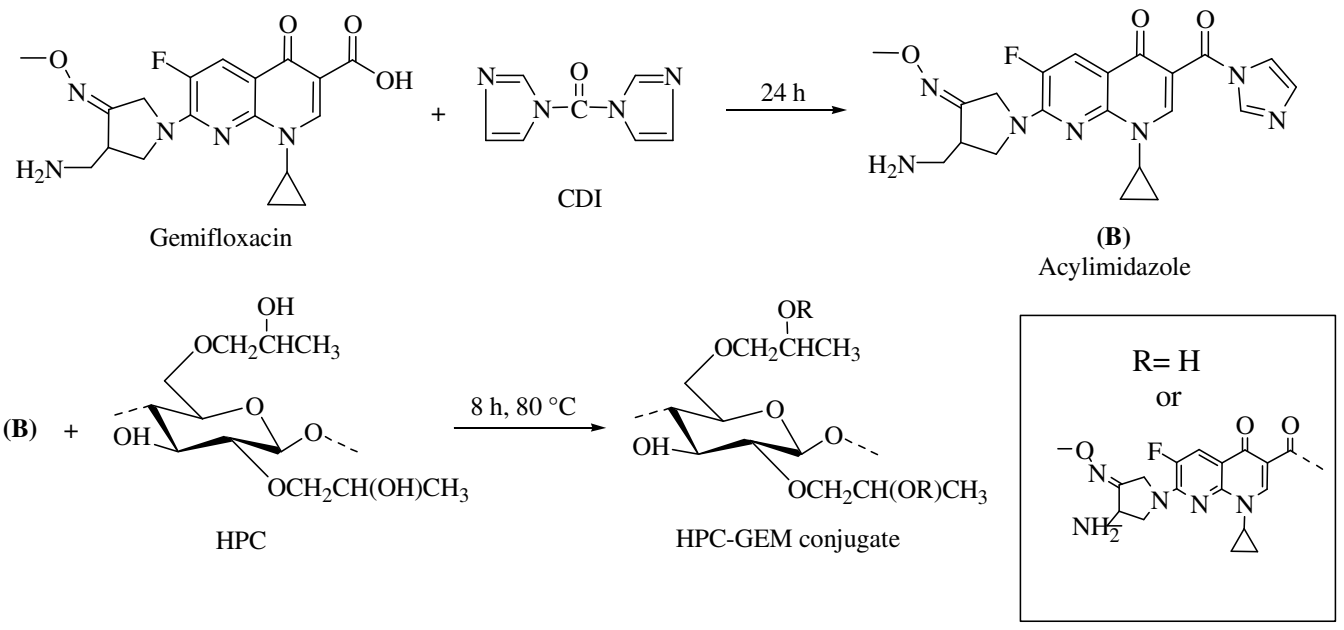

Figure 2: Synthesis of HPC-GEM conjugates $\mathbf{4}$ and $\mathbf{5}$, applying in situ activation of GEM with CDI

Table 2

Results and conditions for reaction of HPC ( $1 \mathrm{~g})$ with GEM after in situ activation with CDI at $80{ }^{\circ} \mathrm{C}$ for $24 \mathrm{~h}$

\begin{tabular}{cccccc}
\hline Sample & Mole ratio $^{\mathrm{a}}$ & Yield (\%) $^{\mathrm{b}}$ & DC & ${ }^{\mathrm{b}}$ DS & Solubility \\
\hline $\mathbf{4}$ & $1: 1: 1$ & 73 & 48 & 0.90 & DMSO, DMAc, DMF, Water \\
$\mathbf{5}$ & $1: 1.5: 1.5$ & 76 & 58 & 1.34 & DMSO, DMAc, DMF, Water \\
\hline
\end{tabular}

${ }^{a}$ HPC: Gemifloxacin: CDI; ${ }^{b}$ DS calculated from DC (by using UV/Vis. data)

This method is highly advantageous, as it generates the imidazole base in situ, which neutralizes the reaction mixture and, in general, no added base is required. The second benefit consists in its high reactivity with carboxylic acid containing drugs. Additionally, it is eco-friendly, hence better than other toxic esterification reagents. Thus, two HPC-GEM conjugates $\mathbf{4}$ and 5 were synthesized and their DS were recorded as
0.90 and 1.34 by UV/Vis spectroscopic data. Both MPDs were precipitated with diethylether and washed with propanol. The data showing the mole ratios, yield, solubility and DS are summarized in Table 2.

\section{Spectroscopic characterization}

The degree of substitution (DS) of HPC-GEM conjugates 1-5 was determined using UV/Vis 
MUHAMMAD AJAZ HUSSAIN et al.

spectroscopy. The amount of the drug loaded per HPC repeating unit, in terms of mg of drug per repeating unit of the polymer, was determined, and the DS was indicated as the number of drug molecules per repeating unit of the polymer. Conjugates 1-5 showed a DS in the range of 0.421.34. This depicts the significant therapeutic applications of the synthesized prodrugs. The yields obtained for the HPC-GEM conjugates were $71-76 \%$.

The FTIR spectra of HPC-GEM 1-5 showed characteristic ester signals $\left(\mathrm{CO}_{\text {Ester }}\right)$ at $1718-1728$ $\mathrm{cm}^{-1}$, which confirmed the success of the esterification reaction. The unmodified hydroxyl groups (-OH) were observed at $2889-2903 \mathrm{~cm}^{-1}$, the COC polymer backbone was found at about 1195-1091 $\mathrm{cm}^{-1}$ and $\mathrm{CH}_{2}$ stretching appeared at $1443-1464 \mathrm{~cm}^{-1}$. The overlay spectra of HPCGEM conjugates 3, 5, HPC and GEM are shown in Figure 3. The FTIR spectra of HPC-GEM 3 and 5 showed ester absorption at $1728 \mathrm{~cm}^{-1}$ and $1722 \mathrm{~cm}^{-1}$, respectively, confirming the covalent loading of the drug to HPC. Methylene stretching was noticed at $1464 \mathrm{~cm}^{-1}$ and $1458 \mathrm{~cm}^{-1}$, and the COC in the polymer backbone was observed in the range of $1051-1202 \mathrm{~cm}^{-1}$. The reduction in intensities of $\mathrm{OH}$ absorption in conjugates $\mathbf{3}$ and $\mathbf{5}$ is another indication of successful esterification reaction and formation of MPDs.

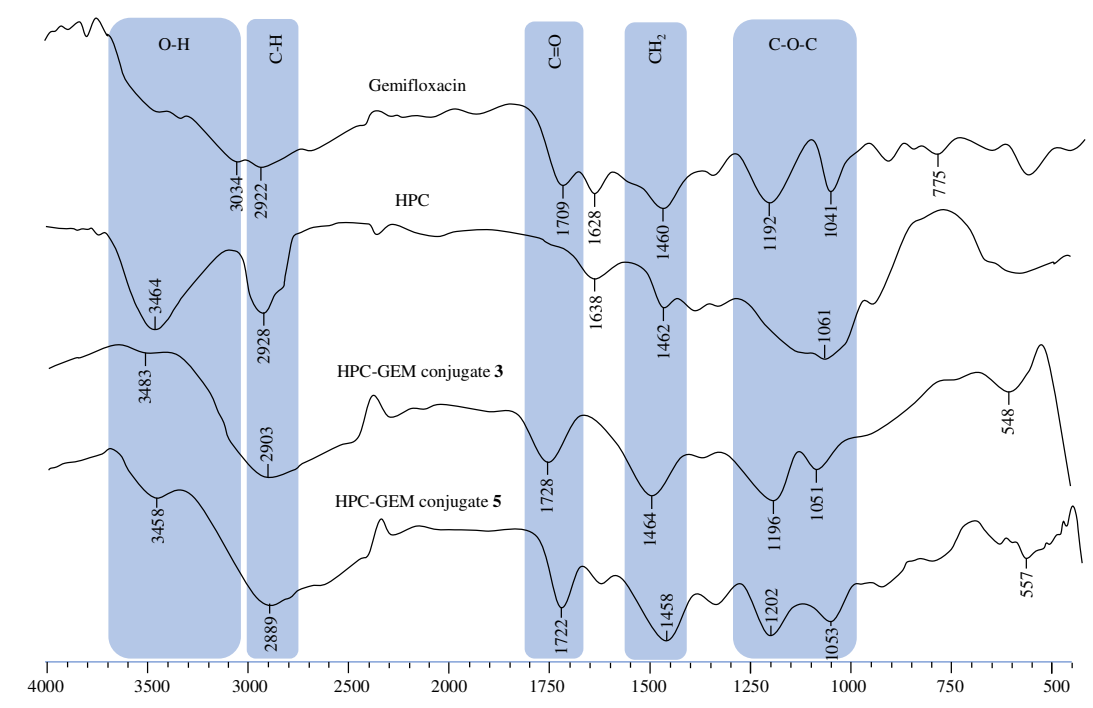

Figure 3: FTIR spectra of gemifloxacin, HPC and HPC-GEM conjugates 3 and $\mathbf{5}$

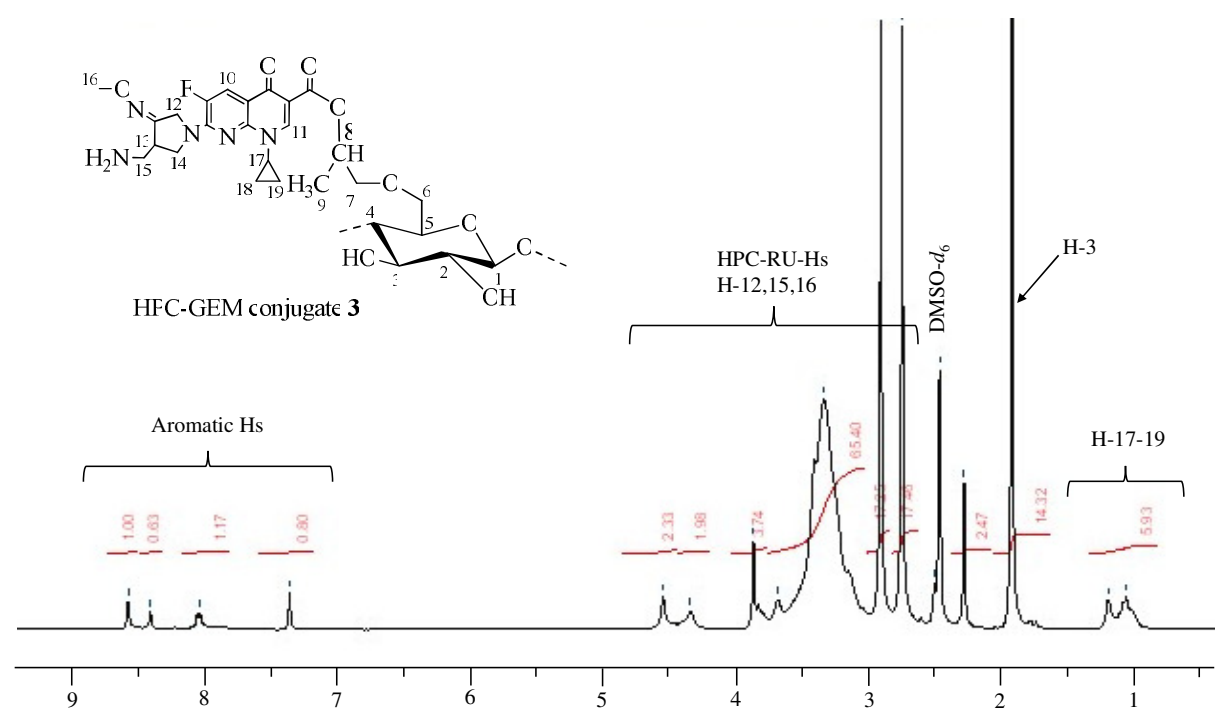

Figure 4: ${ }^{1} \mathrm{H}$ NMR spectrum (500 MHz, DMSO- $d_{6}$ ) of HPC-GEM conjugate 3 


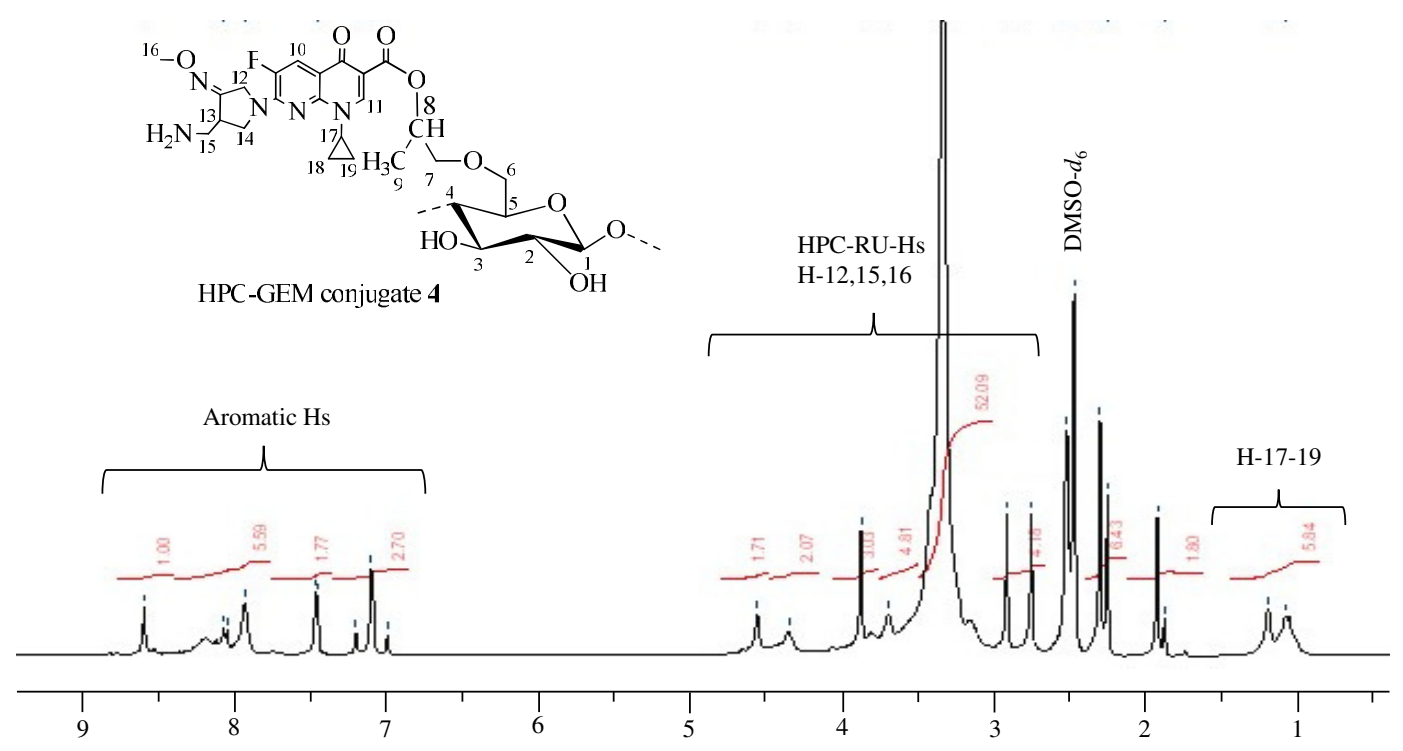

Figure 5: ${ }^{1} \mathrm{H}$ NMR spectrum $\left(500 \mathrm{MHz}, \mathrm{DMSO}-d_{6}\right.$ ) of HPC-GEM conjugate 4

The ${ }^{1} \mathrm{H}$ NMR (400 MHz, DMSO- $d_{6}$ ) spectra of HPC-GEM conjugates 3 (Fig. 4) shows the protons of the HPC polymer anhydroglucose unit (AGU) in the range of $\delta 3.70-4.57 \mathrm{ppm}(\mathrm{H}-1-\mathrm{H}-$ 8). The broader signals at $\delta 2.77-3.35$ show peaks corresponding to the protons of the fivemembered ring of the drug. The peaks at $\delta 1.08$ -

\section{Pharmacokinetic analysis of HPC-GEM conjugate 3}

The bioavailability/pharmacokinetic profiles of the drug and the conjugate were achieved using rabbit models. A simple RP-HPLC/UV method was developed and validated according to $\mathrm{ICH}$ guidelines for investigating pharmacokinetics. Different method validation parameters for HPCGEM conjugates are listed in Table 3. The plot of
$1.22 \mathrm{ppm}$ indicate the protons of the tricyclic ring (H-17-H-19) of the drug attached. The aromatic protons of pyridine were observed at $\delta 7.38-8.59$ $\mathrm{ppm}$. The broadening of the signals indicates the covalent attachment of the drug to the polymer. The ${ }^{1} \mathrm{H}$ NMR (400 MHz, DMSO- $d_{6}$ ) spectrum of HPC-GEM conjugate 4 is also shown in Figure 5. plasma concentration to time for HPC-GEM conjugate 3 and GEM is shown in Figure 6.

The plot shows the delayed release of GEM from the conjugate, in comparison with the pure drug from the rabbit model. The pharmacokinetic parameters also showed higher values of $t_{\max }$ and $\mathrm{t}_{1 / 2}$ for HPC-GEM conjugate (4.0 $\mathrm{h}$ and $25.99 \mathrm{~h}$ ), as compared to the standard GEM ( $2 \mathrm{~h}$ and 15.69 h).

Table 3

Validation parameters of HPC-GEM conjugate $\mathbf{3}$

\begin{tabular}{llc}
\hline No. & Parameter & HPC-GEM conjugate (mean) \\
\hline 1 & Concentration range & $1-5 \mu \mathrm{gL} \mathrm{mL}^{-1}$ \\
2 & LOD & $15 \mathrm{ng} \mathrm{mL}^{-1}$ \\
3 & LOQ & $45 \mathrm{ng} \mathrm{mL}^{-1}$ \\
4 & Linear regression co-efficient $\left(\mathrm{r}^{2}\right)$ & 0.9973 \\
5 & Precision intra-day (RSD)* & $0.753 \%$ \\
6 & Precision inter-day (RSD)* & $0.423 \%$ \\
7 & Accuracy (\% recovery)* & $98.73 \%$ \\
8 & Precision (RSD)* & $0.221 \%$ \\
\hline
\end{tabular}

*Each value is the mean of six observations

The sustained release of HPC-GEM conjugate is supported by the half-life $\left(\mathrm{t}_{1 / 2}\right)$ data, which has higher value for GEM upon oral administration to the rabbits. The bioavailability of the conjugate is 
also greater than that of the drug by comparing the values of $\mathrm{AUC}_{0-\infty}$ of HPC-GEM conjugate and GEM. This enhanced bioavailability of GEM from the conjugate could be of great therapeutic value, similarly to cost effectiveness, lower variability among patients and administration times, and reduced side effects. The longer half- life $\left(t_{1 / 2}\right)$ may offer MIC levels for a longer period of time. Maximum plasma concentrations $\left(\mathrm{C}_{\max }\right)$ for the drug and HPC-GEM are 2.58 and $2.12 \mu \mathrm{g}$ $\mathrm{mL}^{-1}$, which provides one more benefit of lower dosage for the same therapeutic level as offered by GEM. The pharmacokinetic data of the HPCGEM conjugate and GEM are given in Table 4.

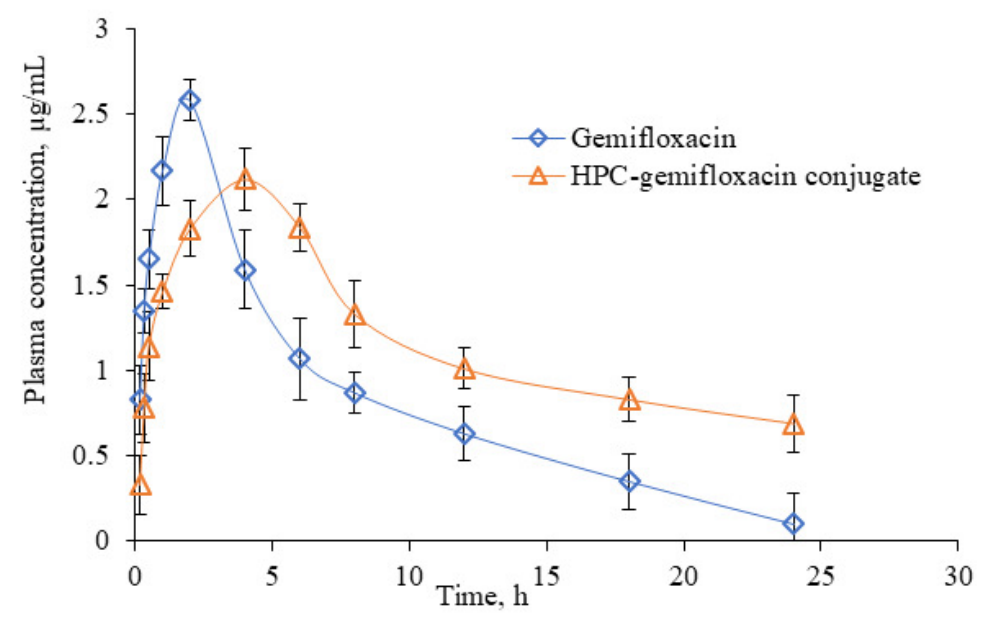

Figure 6: Overlay plot of mean plasma concentration vs. time after oral administration of $63 \mathrm{mg}$ of HPC-GEM conjugate $\mathbf{3}$ (equal to $25 \mathrm{mg}$ of GEM) to rabbits

Table 4

Pharmacokinetic data after a single oral dose of HPC-GEM conjugate 3 (63 mg) equivalent to active drug gemifloxacin $(25 \mathrm{mg})$

\begin{tabular}{lcc}
\hline Parameter & Gemifloxacin & HPC-gemifloxacin conjugate \\
\hline $\mathrm{t}_{\max }$ & $2.0 \mathrm{~h}$ & $4.0 \mathrm{~h}$ \\
$\mathrm{C}_{\max }$ & $2.58 \pm 0.17 \mu \mathrm{g} \mathrm{mL}^{-1}$ & $2.12 \pm 0.13 \mu \mathrm{g} \mathrm{mL}^{-1}$ \\
$\mathrm{t}_{1 / 2}$ & $15.69 \pm 0.74 \mathrm{~h}$ & $25.99 \pm 0.83 \mathrm{~h}$ \\
$\mathrm{AUC}$ & $22.08 \pm 2.3 \mathrm{~h} \mathrm{~g} \mathrm{~mL}^{-1}$ & $54.26 \pm 2.57 \mathrm{~h} \mathrm{~g} \mathrm{~mL}^{-1}$ \\
$\mathrm{Vd}$ & $8.45 \pm 1.02 \mathrm{~L} \mathrm{~kg}^{-1}$ & $5.70 \pm 0.74 \mathrm{~L} \mathrm{~kg}^{-1}$ \\
$\mathrm{Cl}$ & $0.75 \pm 0.09 \mathrm{~L} \mathrm{~h}^{-1}$ & $0.3 \pm 0.04 \mathrm{~L} \mathrm{~h}^{-1}$ \\
\hline
\end{tabular}

\section{CONCLUSION}

Gemifloxacin (GEM) conjugates based on HPC were synthesized successfully using efficient reaction methodology and comprehensively characterized. Pharmacokinetic studies showed that the bioavailability of GEM was enhanced after its covalent attachment onto the HPC backbone and the conjugate showed sustained release characteristics. By forming such prodrugs of different NSAIDs, modeling based on this study, one may alleviate NSAID associated gastric irritancy and obtain an improved pharmacokinetic profile.
ACKNOWLEDGMENTS: I. Shad, I. Malik and M. A. Hussain are thankful to the Higher Education Commission (HEC) of Pakistan for financial support under the scheme "National Research Programme for Universities" (NRPU) and project No. 20-3651. We are thankful to Candid Pharmaceuticals, Sialkot, Pakistan, for the generous gift of GEM (USP). We are also thankful to Dr. Kamran, College of Pharmacy, UOS, and Dr. M. Zaman, College of Pharmacy, UOL, for helpful discussions regarding pharmaceutical analyses. Animal houses of the University of Lahore and the University of 
Sargodha were utilized for animal hosting and caring; hence we are deeply indebted to both of them.

\section{REFERENCES}

I. Morrissey and G. Tillotson, J. Antimicrob. Chemother., $\quad \mathbf{5 3}, \quad 144 \quad$ (2004), https://doi.org/10.1093/jac/dkh092

2 T. Elavarasan, D. Sivakumar and M. Gopalakrishnan, J. Pharm. Res., 12, 749 (2018), https://jprsolutions.info/files/ms-file5b0a3028cea8c7.12916829.pdf

3 R. Wilson, J. J. Schentag, P. Ball and L. Mandell, Clin. Ther., $\mathbf{2 4}, \quad 639 \quad$ (2002), https://doi.org/10.1016/S0149-2918(02)85139-6

4 C. M. Wu, P. J. Wei, Y. T. Shen, H. L. Chang, Y. M. Tsai et al., Antibiotics, 8, 134 (2019), https://doi.org/10.3390/antibiotics8030134

5 E. Özlek, F. S. Biteker, O. Çelik, B. Özlek, C. Çil et al., J. Emerg. Med., 56, e103 (2019), https://doi.org/10.1016/j.jemermed.2019.03.001

${ }^{6}$ FDA Drug Safety Communication, FDA Updates Warnings for Oral and Injectable Fluoroquinolone Antibiotics due to Disabling Side Effects, Safety Announcement, 7 (2018)
7 P. C. Sharma, A. Jain and S. Jain, Acta Pol. Pharm., $\quad$ 66, $\quad 587 \quad$ (2009), https://www.ptfarm.pl/download/?file=File\%2FActa_P oloniae\%2F2009\%2F6\%2F587.pdf

8 M. A. Hussain, K. Abbas, I. Jantan and S. N. A. Bukhari, Int. Mater. Rev., 62, 78 (2017), https://doi.org/10.1080/09506608.2016.1209617

9 K. Abbas, M. A. Hussain, S. N. A. Bukhari, M. Amin, M. N. Tahir et al., Arab. J. Chem., 13, 2101 (2020), https://doi.org/10.1016/j.arabjc.2018.03.011

10 A. Karewicz, K. Zasada, K. Szczubiałka, S. Zapotoczny, R. Lach et al., Int. J. Pharm., 385, 163 (2010), https://doi.org/10.1016/j.ijpharm.2009.10.021

${ }_{11}$ M. A. Hussain, I. Shad, I. Malik, F. Amjad, T. Kausar et al., Saudi Pharm. J., 28, 869 (2020), https://doi.org/10.1016/j.jsps.2020.06.009

${ }_{12}$ T. Heinze, T. Liebert, P. Katy and M. A. Hussain, Cellulose, $\quad \mathbf{1 0}, \quad 283 \quad$ (2003), https://doi.org/10.1023/A:1025117327970

${ }_{13}$ M. A. Hussain, I. Shad, I. Malik, F. Amjad, M. N. Tahir et al., Arab. J. Chem., 13, 5717 (2020), https://doi.org/10.1016/j.arabjc.2020.04.010

${ }_{14}$ M. A. Hussain, K. Abbas, M. Amin, B. A. Lodhi, S. Iqbal et al., Cellulose, 22, 461 (2015), https://doi.org/10.1007/s10570-014-0464-3 